\title{
A case report of 29-year-old male patient with breast carcinoma
}

\author{
Shin-Young Park', Young Up Cho², Sei Joong Kim', Min Hee Hur' \\ ${ }^{1}$ Department of Surgery, Inha University Hospital, Inha University College of Medicine, Incheon; \\ ${ }^{2}$ Department of Surgery, Yonsei University College of Medicine, Seoul, Korea
}

Male breast cancer is a rare disease, accounting for about 1\% of all breast cancers. Little is known about the etiology of male breast cancer, especially developed in young man. Genetic and hormonal factors have been reported to be involved in its pathogenesis. But, less is known regarding the role of anthropometric or other endocrine risk factors. It's extremely rare for breast cancer to occur in young male patient because male breast cancer generally occur in old patients. A 29-year-old male was diagnosed with breast cancer in our institution who was with diabetes and obesity. There was no specific risk of genetic or hormonal factors for his breast cancer.

Keywords: Breast neoplasms, Male, Risk factors, Young

\section{INTRODUCTION}

Breast carcinoma has been dominated disorder in female, whereas breast carcinoma in male is relatively rare accounting for about $1 \%$ of all breast cancers [1]. The mean age at diagnosis for men with breast cancer is older than the average age at diagnosis for women [2]. Several risk factors have been identified, such as genetic and hormonal abnormalities. We present the case of a 29 -year-old man with invasive ductal breast carcinoma, this is the report of the youngest male breast cancer we had experienced.

\section{CASE REPORT}

A 29-year-old Korean man was referred to our institution complaining of progressively enlarging his right breast lump. He had no significant past medical or family history. He was not taking any medication. He was unmarried, but reported normal sexual

Received: Nov 1, 2016 Accepted: Jun 9, 2017

Correspondence to: Young Up Cho

Department of Surgery, Yonsei University College of Medicine, 50-1

Yonsei-ro, Seodaemun-gu, Seoul 03722, Korea

Tel: +82-2-2228-2091, Fax: +82-2-313-8289

E-mail: youngup@yuhs.ac

Copyright ( $($ Korean Society of Surgical Oncology

This is an Open Access article distributed under the terms of the Creative Commons Attribution Non-Commercial License (http://creativecommons.org/licenses/by-nc/4.0) which permits unrestricted non-commercial use, distribution, and reproduction in any medium, provided the original work is properly cited. life and did military service as usual manner. He did not drink alcohol and had a smoking history of 5 pack years. Physical examination revealed $2.5 \mathrm{~cm}$ round mass in lower inner quadrant of right breast. He was an obese person with body mass index (BMI) of $30.4 \mathrm{~kg} / \mathrm{m}^{2}$. He had the normal testis volume.

Mammography revealed a $3 \mathrm{~cm}$ microlobulated, irregular high-density mass at right subareola (Fig. 1). On ultrasonography, the irregular mass at right subareola was measured $4.19 \mathrm{~cm}$ in diameter. The mass had the complex solid and cystic echo pattern with posterior enhancement. The margin of mass was not circumscribed and a long axis of the mass was parallel to the skin. Ultrasonography also showed a suspicious enlarged lymph node at right axilla measured $1.31 \mathrm{~cm}$ in diameter (Fig. 2). The irregular subareolar mass was classified as Breast Imaging-Reporting and Data System category 5 and diagnosed as invasive ductal carcinoma with fine needle aspiration biopsy. There was no systemic metastatic evidence on positron emission tomography-computed tomography (Fig. 3).

The serum study showed elevated carcinoembryonic antigen $(7.44 \mathrm{ng} / \mathrm{mL})$ and hemoglobin Alc (8.9\%) level and showed normal cancer antigen 15-3 $(15 \mathrm{U} / \mathrm{mL})$, estradiol $(21.27 \mathrm{pg} / \mathrm{mL})$ and testosterone $(7.42 \mathrm{ng} / \mathrm{mL})$ level. Genetic analysis was confirmed as eukaryote without chromosomal abnormality and no mutations of BRCA $1 / 2$ genes.

He underwent modified radical mastectomy for his breast cancer and the final pathologic diagnosis was a $3.6 \mathrm{~cm}$ invasive ductal 
carcinoma with histologic grade 3 , nuclear grade 3 , estrogen receptor (ER)-positive, progesterone receptor (PR)-negative, human epidermal growth factor receptor 2 (HER-2)-positive, and Ki-67 labeling index of 50\%. The axillary lymph node dissection showed four positive nodes among 24 lymph nodes retrieved. His final stage was IIIA (T2N2M0).

He underwent adjuvant chemotherapy with 6 cycles of docetaxel, doxorubicin, and cyclophosphamide. And he also un-

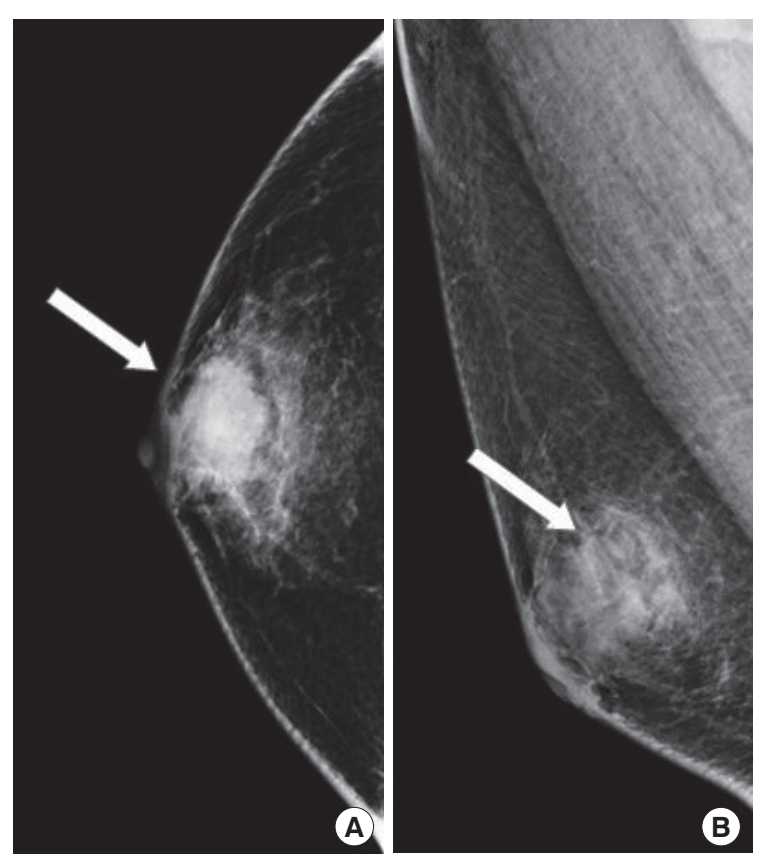

Fig. 1. Mammogram showed a $3 \mathrm{~cm}$ microlobulated, irregular high-density mass (arrows) at right subareola. (A) Craniocaudal view. (B) Mediolateral oblique view.

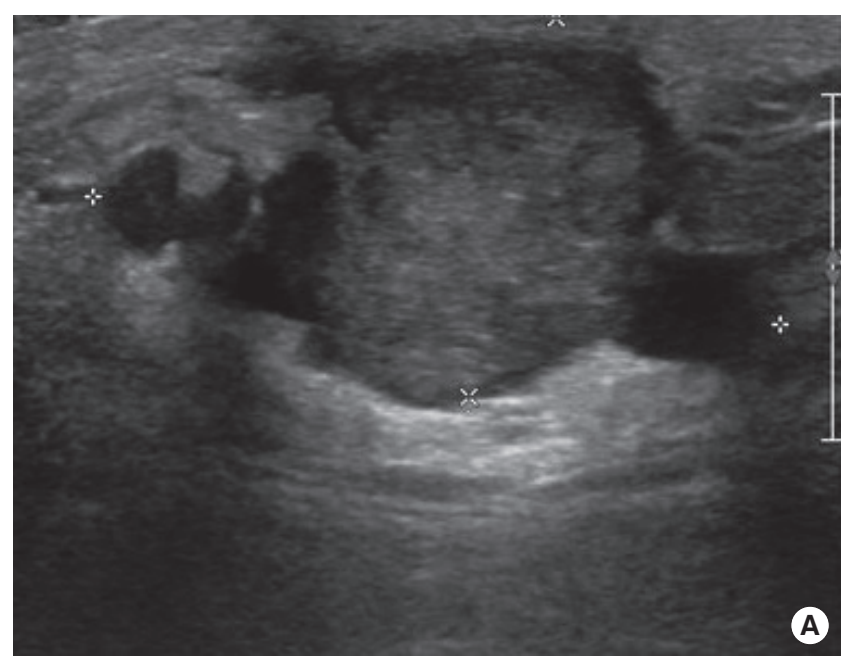

derwent adjuvant radiotherapy, hormonal therapy with daily tamoxifen $20 \mathrm{mg}$, and trastuzumab therapy. Up to now, at 2 years after surgery, there was no tumor recurrence.

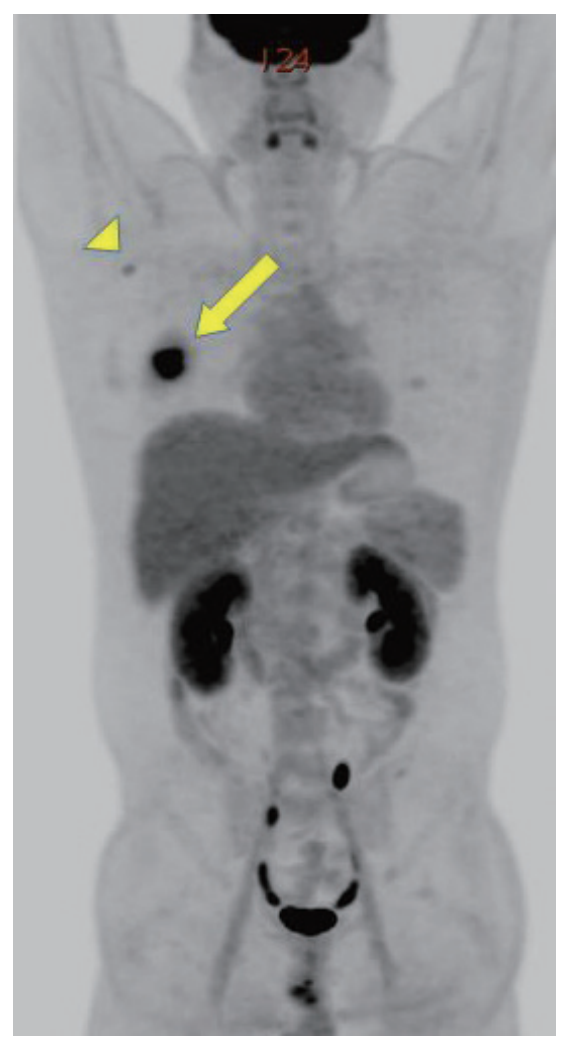

Fig. 3. Positron emission tomography-computed tomography scan showed abnormal fluorodeoxyglucose uptakes in right subareolar breast (arrow) and in right level I axilla (arrowhead). There was no other metastatic evidence.

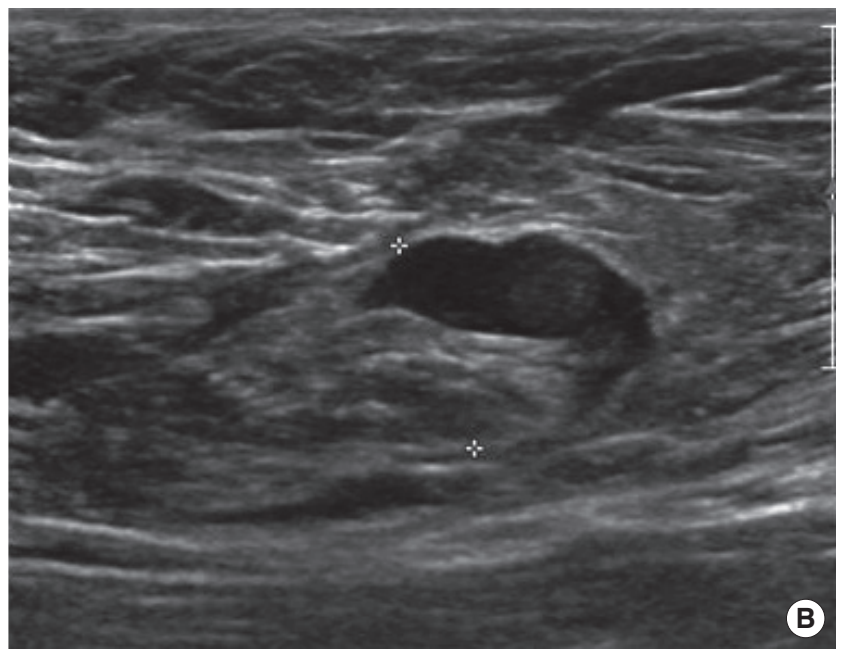

Fig. 2. On ultrasonography, (A) the irregular mass at right subareola was measured $4.19 \mathrm{~cm}$ in diameter and (B) a suspicious enlarged lymph node at right axilla was measured $1.31 \mathrm{~cm}$ in diameter. 


\section{DISCUSSION}

The etiology of male breast cancer is poorly understood, partly because of its relative rarity. But several risk factors have been identified, such as genetic and hormonal abnormalities.

Approximately $15 \%$ to $20 \%$ of men with breast cancer report a family history of breast or ovarian cancer [2]. It is estimated that approximately $10 \%$ of men with breast cancer have a genetic predisposition, and BRCA2 is the most clearly associated gene mutation [3]. BRCA1 mutation is also associated with male breast cancer [4], and associations have also been suggested for CHEK2 mutation [5]. Klinefelter's syndrome (XXY) has been described in the literature as occurring in 3\% to $7.5 \%$ of men with breast cancer [6]. Men with breast cancer should be considered for genetic counseling and testing, and an adequate family history should be obtained. But in this case, the patient had no chromosomal abnormality and no mutation of BRCA $1 / 2$.

Estrogen excess and lack of androgens contribute to several conditions associated to the risk of male breast cancer [2]. Men with Klinefelter's syndrome present testicular dysgenesis, gynecomastia, low testosterone concentrations, and increased gonadotrophins $[2,6]$. But this patient had no hormonal abnormality and had normal testis volume.

It is documented the association of obesity and male breast cancer that is biologically explained by the increased peripheral aromatization of estrogen [2]. The American Association of Retired Persons Diet and Health Study Cohort identified obesity as a risk factor for male breast cancer [7]. Men with BMI of $\geq 30 \mathrm{~kg} / \mathrm{m}^{2}$ had an $80 \%$ increased risk of breast cancer compared with men with BMI of less than $25 \mathrm{~kg} / \mathrm{m}^{2}$. In this case, the patient was obese person with BMI of $30.4 \mathrm{~kg} / \mathrm{m}^{2}$. So, his obesity may contribute to his breast cancer.

Some studies found slightly elevated risk of male breast cancer associated with a history of diabetes. A history of diabetes was related to a modest but statistically significant risk increase [8]. So, his diabetes may contribute to his breast cancer.

Type 2 diabetes has been suggested to increase risk of female breast cancer. Hyperinsulinemia, as occurs in adult-onset diabetes, may promote breast cancer because insulin may be a growth factor for human breast cancer cell [9]. However, many studies have lacked information about the type and severity of diabetes, making the interpretation of various findings difficult. One study showed that female breast cancer with type 2 diabetes had a higher expression of the insulin-like growth factor 1 receptor (IGF1R), and the higher IGF1R was associated with negative human epidermal growth factor receptor 2 (HER-2) expression [10]. However, some study showed that expression patterns of growth factor receptors and membrane proteins in male breast cancer are different from female breast cancer [11].

Alcohol consumption has not been consistently identified as a risk factor for male breast cancer. In a case-control study involving 74 male breast cancers and 1,432 controls, the risk of breast cancer increased $16 \%$ per $10 \mathrm{~g}$ daily alcohol intake [2,12]. But this patient did not drink alcohol.

Epidemiologic studies of male breast cancer are uncommon, and most to date have been small case-control studies, raising the possibility that identified risk factors could reflect the influence of chance or selection and recall biases [8]. There is still a paucity of randomized controlled trials and treatment for male breast cancer is based on treatment for female breast cancer. As in women, men with localized and operable breast cancer are treated with locoregional therapy with surgery plus or minus radiation and systemic therapy with endocrine therapy, chemotherapy, and HER 2-directed therapies. Traditionally, the preferred surgical approach was a modified radical mastectomy. Breast conserving therapy is a possible option for men with breast cancer. However, the lack of adequate surrounding breast tissue and the central location of tumors precludes this approach in some. Recently, there has been an increase in the incidence of male breast cancer, along with the increase in female breast cancer. Further research in the understanding of male breast cancer is warranted to better guide treatment decision-making in these patients.

At the 37th San Antonio Breast Cancer Symposium, Dr Fatima Cardoso from Champalimaud Cancer Centre, Lisbon, Portugal presented the first results of the EORTC (European Organization for Research and Treatment of Cancer) 10085/TBCRC (Translational Breast Cancer Research Consortium)/BIG (Breast International Group)/NABCG (North American Breast Cancer Groups) International Male Breast Cancer Programme [13]. Cardoso and colleagues established a retrospective joint analysis of all male breast cancers diagnosed within the last 20 years and set up a prospective international registry running over 30 months from 278 breast centers. The data analysis showed that median age at diagnosis for males was 68.4 years and male breast cancer received more aggressive surgical intervention (96\% of mastectomies and $76 \%$ of axillary clearance). Adjuvant radiotherapy was mostly correctly provided, but still $36 \%$ of $\mathrm{N} 1$ and $15 \%$ of N2 patients did not receive it. Male breast cancer presents usually as luminal A like subtype, $88 \%$ express androgen receptors, only $1 \%$ is triple negative, and $9 \%$ HER-2 positive. A total of $77 \%$ of male breast cancer is treated by adjuvant endocrine therapy-mainly tamoxifen (88\%) - and the ER and PR status being prognostic with high expression associated with better outcomes.

Overall survival of male breast cancer is similar to that of wom- 
en with breast cancer. Similar to women with breast cancer, stage, tumor sized, and axillary lymph node status are important factors influencing outcome. The impression that male breast cancer has a worse prognosis may stem from the tendency toward diagnosis at a later stage [2]. Some studies have found the distribution of tumor subtypes in male breast cancer to be different compared with female breast cancer, which may point to important differences in biology and outcomes [14].

Now, Advancements in the characterization and genomic mapping of male breast cancer have been discussed. It is hoped that these huge efforts for rare disease are able to derive more results for understanding of male breast cancer.

\section{CONFLICT OF INTEREST}

No potential conflict of interest relevant to this article was reported.

\section{ACKNOWLEDGMENTS}

This study was supported by Inha University Hospital Research Grant.

\section{REFERENCES}

1. Siegel RL, Miller KD, Jemal A. Cancer statistics, 2016. CA Cancer J Clin 2016;66:7-30.

2. Sousa B, Moser E, Cardoso F. An update on male breast cancer and future directions for research and treatment. Eur J Pharmacol 2013;717:71-83.

3. Couch FJ, Farid LM, DeShano ML, Tavtigian SV, Calzone K, Campeau L, et al. BRCA2 germline mutations in male breast cancer cases and breast cancer families. Nat Genet 1996;13:123-5.

4. Brose MS, Rebbeck TR, Calzone KA, Stopfer JE, Nathanson KL, Weber BL. Cancer risk estimates for BRCA1 mutation carriers identified in a risk evaluation program. J Natl Cancer Inst 2002;
94:1365-72.

5. Meijers-Heijboer H, van den Ouweland A, Klijn J, Wasielewski M, de Snoo A, Oldenburg R, et al. Low-penetrance susceptibility to breast cancer due to CHEK2 $\left(^{*}\right) 1100 \mathrm{delC}$ in noncarriers of BRCA1 or BRCA2 mutations. Nat Genet 2002;31:55-9.

6. Hultborn R, Hanson C, Kopf I, Verbiene I, Warnhammar E, Weimarck A. Prevalence of Klinefelter's syndrome in male breast cancer patients. Anticancer Res 1997;17:4293-7.

7. Brinton LA, Richesson DA, Gierach GL, Lacey JV Jr, Park Y, Hollenbeck AR, et al. Prospective evaluation of risk factors for male breast cancer. J Natl Cancer Inst 2008;100:1477-81.

8. Brinton LA, Cook MB, McCormack V, Johnson KC, Olsson H, Casagrande JT, et al. Anthropometric and hormonal risk factors for male breast cancer: male breast cancer pooling project results. J Natl Cancer Inst 2014;106:djt465.

9. Freiss G, Prebois C, Rochefort H, Vignon F. Anti-steroidal and anti-growth factor activities of anti-estrogens. J Steroid Biochem Mol Biol 1990;37:777-81.

10. Xin C, Jing D, Jie T, Wu-Xia L, Meng Q, Ji-Yan L. The expression difference of insulin-like growth factor 1 receptor in breast cancers with or without diabetes. J Cancer Res Ther 2015;11:295-9.

11. Vermeulen JF, Kornegoor R, van der Wall E, van der Groep P, van Diest PJ. Differential expression of growth factor receptors and membrane-bound tumor markers for imaging in male and female breast cancer. PLoS One 2013;8:e53353.

12. Guenel P, Cyr D, Sabroe S, Lynge E, Merletti F, Ahrens W, et al. Alcohol drinking may increase risk of breast cancer in men: a European population-based case-control study. Cancer Causes Control 2004;15:571-80.

13. Ahmed M, Esposito E. Report from the 37th san antonio breast cancer symposium, 9-13th december 2014, Texas, USA. Ecancermedicalscience 2015;9:508.

14. Kornegoor R, Verschuur-Maes AH, Buerger H, Hogenes MC, de Bruin PC, Oudejans JJ, et al. Molecular subtyping of male breast cancer by immunohistochemistry. Mod Pathol 2012;25:398-404. 